\title{
On Safe Space in Education: A Polish-Vietnamese Comparative Study
}

\author{
Dorota Domalewska ${ }^{1, *}$, Małgorzata Gawlik Kobylińska ${ }^{2}$, Phuong Hoang Yen ${ }^{3}$, Rebecca K. Webb ${ }^{4}$ and Nakonthep \\ Thiparasuparat ${ }^{4}$ \\ ${ }^{1}$ Faculty of National Security, War Studies University, Warsaw, Poland \\ ${ }^{2}$ Faculty of Management and Command, War Studies University, Warsaw, Poland \\ ${ }^{3}$ Department of English Language and Culture, Can Tho University, Can Tho, Vietnam \\ ${ }^{4}$ Faculty of Liberal Arts, Rangsit University, Rangsit, Thailand \\ Corresponding author: d.domalewska@akademia.mil.pl
}

Submitted: 15 January 2021 | In revised form: 27 April 2021 | Accepted: 22 June 2021 | Published: 25 August 2021

\begin{abstract}
Safe space describes a classroom climate that feels secure, supportive, and risk-free so that students can honestly express their individuality and opinions without fear of being the target of violence, harassment, or hate speech. In this paper, we examine the relationship between the school environment, individual characteristics and family in shaping students' perceptions of a safe learning environment. The Safe Learning Environment Survey was designed and distributed to a convenience sample of 360 undergraduate students at universities in Poland and Vietnam. Results reveal that neither sex nor family context affect students' feeling of safety at school. However, feeling safe at school is significantly associated with students' cultural background. Polish and Vietnamese students differ in their opinions as to why safe space should be enhanced and in terms of what the roles of the teacher and their peers are in shaping safe atmospheres. These findings have significant implications for multicultural classes: understanding the factors that enhance school safety will help to form a collaborative and inclusive environment where students' performance improves.
\end{abstract}

Keywords: Intercultural learning; Polish-Vietnamese comparative study; safe space; school safety

\section{Introduction}

Learning space has been a central topic of pedagogy, traditionally understood as a physical, brick and mortar learning environment $[1,2]$ where face-to-face lectures constrained learning in terms of time and space. Numerous perspectives on learning, such as the Social Learning Theory (e.g. [3]), Sociocultural Theory of Learning (e.g. [4]), and Situated Learning (e.g. [5]), ascertain that most learning takes place beyond formally designated learning spaces [6]. Even though the educational system provides formal instruction in a planned and organized manner that is imposed by the curriculum, much of the learning takes place through socializing agents: adults (teachers or other school employees) and peers, where the development of not only cognitive, but also social and affective dimensions takes place. Therefore, learning space, or positive space, is a place where students assimilate knowledge, behavior, and thinking as well as shape their attitudes, norms, values and opinions through interaction with others. It is frequently an environ- 
ment where transition, or in some cases transformation, takes place when students "experience a shift or reorientation in their life world" [7] due to a change in identity or role perception, so that they perceive the world in a different way. Therefore, it is important that learning space is a safe space where students feel secure enough to openly express their opinions, share their attitudes, and take risks so that their performance is enhanced and the outcomes improved. In this paper, we hope to contribute to the debate about safe space in education by putting forward a crosscultural perspective on fostering and maintaining safety in the educational context globally. It should be mentioned that the expression 'taking risks' in education is related to specific behavior which may encounter negative feedback from social environments. Such feedback negatively affects interpersonal relations. Safe space is risk free as it constitutes 'brave space', namely, an environment free from abuse and ridicule. On the other hand, [8] argues that real education always involves risk. The author identifies seven key educational areas: creativity, communication, teaching, learning, emancipation, democracy, and virtuosity and argues that 'taking risk' in adverse conditions may lead to negative experiences that impede personal and social development in any of the abovementioned areas.

The cross-cultural perspective will consider two nations: Poland and Vietnam. The rationale for conducting the comparative research is related to closer PolishVietnamese relations, which concerns educational migration and economic-oriented migration $[9,10]$. It will also provide a theoretical framework for other similar comparative research on this topic.

Understanding the factors that undermine school safety will help to reduce the long-term negative outcomes of victimization at school and reduce the risk of exposure to an unsafe school environment. Despite the importance of the topic of school safety, there remains a paucity of evidence on individual characteristics and school context on students' perception of a safe learning environment. Furthermore, there have been no studies which compare national differences in the perception of school safety. This paper explores the ways in which the school environment, i.e. teachers, peers, students themselves, and individual characteristics such as sex nationality and family affect students' perceptions of a safe learning environment. This study makes a major contribution to research in education by demonstrating individual differences in the perception of school safety. Previously published studies are limited to local surveys that focus on the low socio-economic context of ethnic groups. This is the first study to investigate how students with different cultural backgrounds (Polish and Vietnamese) perceive school safety.

\subsection{Safe Space Definition}

The concept of safe space originates from the 1970s feminist and LGBT movement. It originally referred to a meeting place where marginalized people could meet and share their experiences without discrimination [11]. Safe space programs or safe zones at schools and universities were established, e.g. at a classroom or an educator's office where marginalized youth could feel at ease and discuss issues that troubled them. Receiving such support, even being aware that there is a place they could go to find support, helped to build their sense of self, form a supportive community and cope with bias [12]. As a result, communities of people flourished, especially at university campuses or workplaces, e.g. EQUAL!, an educational and support group in Nokia Corporation (https://equal.org/), but also in primary schools in the UK [13], US and Canada [14]. The communities brought together understanding and trustworthy people who were supportive of LGBTQIA+ people if they needed advice. More recently, safe space policies at universities have been criticized for inhibiting the freedom of speech as they prevent contested issues from being discussed $[15,16]$.

Safe-space classrooms in educational institutions differ from the safe-space policy in higher education institutions or workplaces because the rules and goals of cohabitation differ [11]. Therefore, safe space describes a classroom climate that feels secure, supportive and risk-free so that students can honestly express their individuality, opinions, attitudes, knowledge, and behavior [17] without fear of being the target of violence, harassment or hate speech. Safety in this context exceeds physical safety and "refers to protection from psychological or emotional harm" [17]. Safe learning space entails creating a positive atmosphere that encourages students to break down their isolation, form an inclusive and collaborative classroom community [12,18,19], which is encouraging for expression without fear of ridicule and supports their well-being, resilience and moral identity [19]. Moreover, a safe learning environment correlates with the performance of students [20], especially in programs for troubled teens [21].

The climate of safe space is the main precondition for both intercultural dialogue and exploring the diversity of opinions, values and attitudes [22,23]. Therefore, cultivating safe-space encourages self-disclosure in students despite the fear of negative consequences following such disclosure [17] because a climate of safe space does not entail comfort. In order to develop cognitively, emotionally and socially, students need to experience challenges and struggles [4,24]. In an environment where not only knowledge but also identity can be challenged, students' learning and creativity can flourish [7]. However, a learning space rich in engagement, challenge and struggle will not be free from conflict. Discussion, especially on controversial issues, may easily steer from polite to provocative and tensions might arise; that is why [25] suggests replacing the concept of safe-space classrooms, which is for him too ambiguous, with the notion of communities of disagreement, which he defines as "a group with identity claims, consisting of people with different opinions, who find themselves engaged in a common process, in order to solve shared problems or challenges". Similarly, Arao \& Clemens [26] criticize the 
concept of safe space for giving students false ideas of safety and being too closely related to power relations. In turn, the researchers suggest using the notion of brave space because, in order to engage in authentic learning and dialogue about diversity, both students and teachers need to be ready to put themselves at risk and challenge their comfort zones, which requires bravery, not the illusion of safety. However, regardless of the term used to denote a supportive learning environment, the researchers emphasize the need to make classrooms pro-social spaces where a variety of individuals get along and are respectful to one another despite their differences in race, ethnicity, language, religion, gender, individual or personal qualities. The climate of safe space therefore entails forming an environment free from abuse, manipulation and unstable social links, which can be done by developing students' communication skills $[19,27]$ and implementing effective classroom management [28], including setting ground rules that all students and school staff comply with. Establishing guidelines for participation and contribution should be the outcome of shared collaborative work between teachers and students because commonly established rules help to develop trust and safety [29]. Ground rules include using appropriate language devoid of racist, sexist comments and hate speech, challenging ideas, but not the individuals who express them, justifying opinions that have been expressed and giving everyone the opportunity to voice their opinion [23], respecting one another, and not taking things personally [26].

\subsection{Shaping Safe Space Perceptions}

The structure of a learning space is formed on the one hand by externally imposed institutional norms, and on the other hand, by the needs and expectations of the community that has established the space. An environment that is conducive to learning includes the following components: physical resources (e.g. materials, technology, and the classroom) and the social groups students interact with [29]: teachers and peers. The quality of relationships at school, at home and in the community plays a significant role in forming a safe and supportive learning space. In this study, we are going to focus on two elements that form the safe space: the students themselves (individual context) and their peers, teachers, and family.

\subsection{Individual Factors and Family}

Individual-level characteristics, such as age, sex, nationality and family background have an impact on students' perception of what safe space is [30,31]. A larger percentage of primary than secondary school students are afraid of being attacked or harmed. These findings are, however, inconsistent, because other studies $[32,33]$ found that middle and high school students tend to have more school safety concerns than primary school students.

A higher percentage of male than female students provoked disciplinary incidents, whereas more female students reported feeling unsafe at school and avoided school activi- ties or certain places in the school for fear of being attacked or harmed $[34,35]$. Female students are more likely to experience gender-related harassment and sexual crimes, which contributes to them perceiving the school environment as more dangerous [36]. Other studies, however, reveal contrasting results. Akiba [37] and Welsh [38] provide evidence that more male than female students tend to fear for their safety at school. Mijanovich and Weitzman [39] have not found evidence for any correlation between gender and fears about safety at school.

The family context can be associated with perceptions of safety at school, in particular parental involvement with children and feelings of isolation $[34,40]$. However, other studies [33] found that parental school involvement is not correlated with a perception of school safety. Students' low socio-economic status increases the risk of perceiving school as an unsafe environment $[33,39,41]$. This may be related to the fact that students with low socio-economic status live in impoverished areas with higher rates of misbehavior. They are, therefore, more frequently exposed to bullying and other crimes, which is projected onto feelings of threat and insecurity at school.

\subsection{School Environment}

The school environment determines students' concerns about safety at school. Students attending disorderly schools that fail to impose regulations are more concerned about their safety [37-39]. The school climate is more strongly correlated with the perception of safety in schools that are located in high socio-economic status communities [42].

Teachers' behavior affects students' perception of safety at school. Learners feel less threatened and more comfortable when teachers adopt student-centered approaches, which may be related to the fact that these teachers take more interest in their students [37]. Students who enjoy a close relationship with their teachers feel safe at school [34].

Peer relations may cause safety problems. Students who remain isolated tend to be concerned about victimization at school $[34,40]$. Other factors that instill concern for one's safety include the presence of gangs [41], large school size [43] and the presence of school security measures, such as metal detectors, security guards, and surveillance cameras [44]. Significant analysis and discussion on the subject was presented by Juvonen, Nishina and Graham [45] who studied the perception of safety among ethnic minorities. High classroom diversity not only lowers concerns for their safety among minority students but also empowers learners to cope more effectively with the emotional effects of threat and stress. Furthermore, heterogeneous classrooms contribute to critical thinking skills among students [46], reduce prejudice and improve social integration $[47,48]$.

\subsection{Polish and Vietnamese Cross-Cultural Characteristics}

Veerasamy \& Laakso [49] state that "cultural attitudes impact the way students participate in education"; therefore, 
it is important to focus on the cultural background of the two countries. The culture is key to the understanding of perspectives which govern the principles underlying the treatment and approach to safe space in education. Culture, as with the sharing of common experiences in communities, manifests itself at different layers of depth. It is expressed in social behavior, norms shared, as well as in knowledge, beliefs, arts, laws, customs, capabilities, and habits of the individuals. The Hofstede framework was applied in the cultural analysis of the countries as it was assessed as stable. The findings suggest that "although cultural change has occurred, it has occurred in the same way for all societies, leaving countries' relative positions largely unaffected" [50]. On the basis of the theory of Geert Hofstede [51], five dimensions were analyzed: power distance, individualism-collectivism, masculinity-femininity, uncertainty avoidance, and short-term orientation-long-term orientation. Later, a sixth dimension, indulgence-restraint, was added [52]. Power distance, strength of social hierarchy, is defined as "the extent to which the less powerful members of organizations and institutions (like the family) accept and expect that power is distributed unequally" [51]; individualismcollectivism - is "the degree to which people in a society are integrated into groups" [53]; masculinity-femininity, taskorientation versus person-orientation, is "related to the division of emotional roles between women and men" [53]; uncertainty avoidance is "the level of stress in a society in the face of an unknown future"; and short-term orientation-longterm orientation, concerns "the choice of focus for people's efforts: the future or the present and past". The sixth dimension, indulgence-restraint orientation refers to "the gratification versus control of basic human desires related to enjoying life" [53]. With regard to the measures, there are six scale intervals (1-20), (21-40), (41-60), (61-80), (81-100), and (101-120) which are used in describing the intensity of a given dimension.

\subsection{Cultural Dimensions of Vietnam}

Thi \& Nguyen [54] stress that the Vietnamese values system is affected by the philosophical or religious systems of Confucianism, Taoism and Buddhism. This is reflected in the studious spirit, family obligations, the desire for reputation, respecting others and harmony. More specific Confucian values bring respect for social hierarchy, order, and maintaining social harmony [55]. What is more, the Vietnamese have adapted Western values from the French and Americans, which is reflected in the emergence of individualism, liberty, equality and democracy [54]. The author also notices that due to political conditions, socialist values are promoted as key rulers of social well-being and prosperousness [54]. Any topics which may be seen as inflammatory are rather forced out of social and political discourse. For instance, the LGBT movement in Vietnam is not legally protected and the groups are socially marginalized; a heterosexual couple with two children is the model promoted in the media and politics [56].
Regarding the cultural dimensions analysis, the power distance index (PDI) is 70 for the Vietnamese, the individualism index (IDV) - 20, masculinity index (MAS) - 40, uncertainty level index (UAI) - 30 [48,52], long-term orientation index (LTO) - 57 [54], and indulgence-restraint index (IVR) - 35 [52]. A high score for the power distance means that the society tends to accept a hierarchical order with inherent inequalities. The individualism score of 20 is low, which means that Vietnam is a collectivistic society. In a collectivistic society, loyalty influences societal rules and regulations, and responsibility for others; any offence causes shame and loss of face. The index of 40 indicates that Vietnam is a feminine culture, which is expressed in caring for others and quality of life, equality, solidarity and quality in their working lives, and compromise. A very low uncertainty level, i.e. 30, signifies that the Vietnamese tend to establish laws, rules, regulations and control mechanisms to prevent any ambiguity or risk, and if they are ambiguous or do not work they should be abandoned or changed. According to Nguyen and Truong [57], on a daily basis, "Vietnamese people are quite flexible and easy adapt to real-life situation, sometimes they believe that everything happening depends on fate." The Vietnamese tend to be characterized as long-term orientated, which refers to family pragmatism, sustained efforts toward slow results, and revealing respect for circumstances. It is worth noting that in comparison to other cultures strongly influenced by Confucianism, it is a significantly low score. In the last dimension, Vietnam is a restrained culture which is governed by social norms.

\subsection{Cultural Dimensions of Poland}

Poland, an ex-communist society, with a long but lost history of multiculturalism, is oriented toward survival and traditional values. The values are closely related to Catholicism, which affect many areas of life. Some authors even notice that "interventions of the Roman Catholic Church in state affairs are made regularly" [58], or "religion is central to political identity" [59]. This significantly shapes the attitude towards inflammatory issues. Similarly to other post-socialist countries, Poland is characterized by low gender egalitarianism $[60,61]$. With regard to safe space in education, most resources are in Polish and they concentrate on the general need for taking into account such a concept in culturally diverse environments. It is more a discourse on the need for cross-cultural education, as well as developing sensitivity both towards one's own and foreign culture, which also contributes to opening a safe space in education. The other characteristics of the society are based on the six dimensions. For Poland, the PDI is 68, IDV-60, MAS-64, UAI-93, LTO-32, and IVR-29 [52]. In relation to the relatively high PDI, Poland, similar to Vietnam, is a hierarchical society. The IDV (60) indicates that Poland is an individualist society, where individuals tend to take care of themselves. As a rather masculine culture, its society is driven by competition and achievement. A very high UAI reveals that Poland prefers to maintain control over the 
future by applying rigid codes of belief and behavior; it is not tolerant to any kind of unorthodox behavior. The low LTO suggests Poles are more normative than pragmatic in their thinking and behavior, respecting traditions, tending to believe in absolute truth, expecting quick results, and because of the restrained culture, Poles have a tendency to be cynical and pessimistic [62].

It is noticeable that Poland and Vietnam have different backgrounds and experiences with social diversity. With regard to Hofstede's analyses of cultural dimensions, some orientations, such as PDI and IVR are very similar. The remaining dimensions either differ significantly (IDV, UAI) or in a moderate way (MAS, LTO). The differences may underlie the perception of safe space in education.

\section{Method}

This research aims to provide an answer to the research question concerning the perception and experiencing safe space in education: What is the relationship between the school environment, individual characteristics and family in shaping students' perceptions of a safe learning environment? We hypothesize that female students with a low socio-economic status and with low parental closeness perceive the school environment as unsafe $(\mathrm{H} 1)$. Furthermore, we think that students' perceptions on safe space in education vary across cultures $(\mathrm{H} 2)$.

The Safe Learning Environment Survey was designed to assess students' perceptions of the impact of the school environment and individual characteristics on the learning environment. The survey was developed based on previous research carried out by Flensner and Von der Lippe [11] and Holley and Steiner [17]. The survey comprised 58 questions divided into 3 sections (see appendix $A 1$ ). The first section contained 43 Likert-scale questions addressing school-level factors (teachers, peers and students themselves) on students' perception of safe space in education. The impact of teachers either enhanced the positive space, which was measured with 10 items (positive space - teacher scale) or it resulted in unsafe perceptions of the school environment, which was measured with 6 items (negative space - teacher scale). Similarly, the impact of peers on safety perception was either positive, which was measured with 6 items (positive space - peers scale) or negative, which was measured with 5 items (negative space - peers scale). Students themselves also play a role in creating class atmosphere. A positive impact was measured with 9 items (positive space - self scale) whereas a negative impact was measured with 4 items (negative space - self scale). The questions were multiple choice questions and the respondents could select any number of answers.

The respondents' perception of school safety included 5 items (perception of safety scale). Response options ranged from $1=$ strongly disagree to $5=$ strongly agree. Finally, the survey included 5 items referring to individual characteristics of the respondents: sex (male, female), lowhigh family socio-economic status (SES) (the occupation of both parents is either employed part-time, unemployed or unable to work), and parental closeness - remoteness. The questionnaire was piloted using 50 undergraduate students in Poland. Based on the research analysis, some of the original questions were deleted because they provided redundant information.

The survey was distributed from August to October 2019 to a convenience sample of 360 undergraduate students at universities in Poland ( $\mathrm{N}=221)$ and Vietnam $(\mathrm{N}=139)$. It was made available in both paper form and web-based form. Prior to answering the survey questions, the students were informed about the purpose of the study. The respondents were asked to answer the questions with respect to their general approach to learning. The confidentiality of responses was ensured by maintaining the anonymity of the subjects. Participation in the study was voluntary. The time required to complete the questionnaire was approximately 10 minutes.

\subsection{Data Analysis}

Descriptive statistics (see appendix A1) were used to describe respondents and to report the results of respondents' responses to survey questions. Frequency and standard deviation (SD) show the distribution of the answers. Inferential statistics were used to investigate differences among the variables. The Kolmogorov-Smirnov and the Shapiro-Wilk tests for normality were employed to assess the distribution of the data. The Kruskal-Wallis test was used to derive conclusions about significant differences between dependent measures as a function of specific demographic variables including sex, socio-economic status, family closeness and nationality.

\section{Results}

As shown in appendix $A 1$, the sample consisted of $39.4 \%$ male and $60.6 \%$ female respondents of two nationalities: Polish (61.4\%) and Vietnamese (38.6\%). 12.5\% of the sample were of low socio-economic status for whom both parents' occupation was either employed part-time, unemployed or unable to work. At the family level, the mean score of the low parental closeness was $58.9 \%$.

The distribution of PSS, NSS, PS and NST is more symmetrical; however, the SD is high for all scales. The distribution of data is therefore highly varied. Variables representing the school level factors were teacher attitude, peers' attitude and the attitude of the students themselves. The respondents from Poland most frequently marked the following three features of the teacher that contributed to safe space at school: being respectful and supportive (31.1\% of the Polish respondents marked this answer), unbiased and non-judgmental (24.4\%), challenging students and posing questions (23.3\%). The Vietnamese students marked the following three teacher qualities as contributing to a positive atmosphere at school: being informative and knowledgeable (19.4\%), being respectful and supportive (15.8\%), 
being friendly and caring (15.5\%). Both Polish and Vietnamese students agreed that the following teacher features disrupted the perception of safety at school: being biased, opinionated or judgmental (indicated by $27.2 \%$ of Polish students and $25 \%$ of Vietnamese students) and being critical, chastising students and shooting down their ideas (indicated by $25 \%$ of Polish students and $23 \%$ of Vietnamese students).

The behavior and attitude of classmates may promote the feeling of safety at school, especially if they honestly share thoughts, ideas, opinions, and facts (according to $35.5 \%$ of Polish and $20.5 \%$ of Vietnamese respondents), have positive attitudes (24.1\% Polish and $23.6 \%$ of Vietnamese students), and are respectful, listen and follow ground rules $(23.6 \%$ of Polish and $21.6 \%$ of Vietnamese respondents). The behavior of peers also compromises the feeling of safety. According to Polish students, it is disruptive when classmates try to please the teacher (this answer was given by $36.6 \%$ of the respondents), are biased, judgmental or close-minded (32.5\%) and frustrated, angry or hostile $(23.8 \%)$. For Vietnamese students, safety at school is compromised if classmates do not speak or are afraid to speak $(28.8 \%)$, are apathetic about the course $(27.2 \%)$ and try to please the teacher $(22.2 \%)$.

Safety at school is promoted when students themselves are open-minded and consider the views of their classmates (30.5\% of Polish and $18.8 \%$ of Vietnamese respondents), honestly share ideas, views and values $(22.7 \%$ of Polish and $13.8 \%$ of Vietnamese respondents), and are supportive and respectful towards others (19.1\% of Polish and $21.3 \%$ of Vietnamese respondents). On the other hand, safety is compromised when students are not confident $(31.3 \%$ of Polish and $33 \%$ of Vietnamese respondents), are fearful, worried, intimidated and insecure $(29.4 \%$ of Polish and $24.1 \%$ of Vietnamese respondents), and do not invest in the course $(30.8 \%$ of Polish and $22.5 \%$ of Vietnamese respondents).

Both Polish and Vietnamese students believe that it is important to create safe space in the classroom where students can freely speak their mind $(48.6 \%$ of Polish and $37.7 \%$ of Vietnamese students agree with this option).

The Kolmogorov-Smirnov statistic takes a value between 0.119 and 0.405 (Table 1), whilst the Shapiro-Wilk statistic takes a value between 0.646 and 0.952 . The $p-$ value is 0.000 . Therefore, we reject the hypothesis that the variable follows a normal distribution. The Shapiro-Wilk's test agrees with the Kolmogorov-Smirnov p-value $<0.05$. The skewness ranges from 0.225 to 1.170 . The skewness value for the PSS and NSS scales is approximately symmetric. For other scales, the skewness is high but acceptable.

To test our research hypotheses, we observed the correlation between independent variables (sex, socio-economic status, parental closeness, and nationality) and the perception of school safety in class, in particular the impact of teachers, classmates and the students themselves on shaping a safe environment. The findings are in Table 2.

Table 1. Kolmogorov-Smirnov and Shapiro-Wilk test

\begin{tabular}{|c|c|c|c|c|c|c|c|}
\hline \multirow[t]{2}{*}{ Variable } & \multicolumn{3}{|c|}{ Kolmogorov-Smirnov test } & \multicolumn{3}{|c|}{ Shapiro-Wilk test } & \multirow[t]{2}{*}{ Skewness } \\
\hline & Statistic & Df & p-value & Statistic & Df & p-value & \\
\hline Positive space - teacher (PST) & 0.392 & 357 & 0.000 & 0.659 & 357 & 0.000 & 1.170 \\
\hline Negative space - teacher (NST) & 0.391 & 357 & 0.000 & 0.721 & 357 & 0.000 & -0.931 \\
\hline Positive space - peers (PSP) & 0.362 & 357 & 0.000 & 0.759 & 357 & 0.000 & -1.138 \\
\hline Negative space - peers (NSP) & 0.398 & 357 & 0.000 & 0.693 & 357 & 0.000 & -1.047 \\
\hline Positive space - self (PSS) & 0.405 & 357 & 0.000 & 0.646 & 357 & 0.000 & 0.225 \\
\hline Negative space - self (NSS) & 0.309 & 357 & 0.000 & 0.754 & 357 & 0.000 & -0.371 \\
\hline Perception of safety (PS) & 0.119 & 357 & 0.000 & 0.952 & 357 & 0.000 & -0.776 \\
\hline
\end{tabular}

Table 2. Kruskal-Wallis test

\begin{tabular}{|c|c|c|c|c|}
\hline Variable & $\begin{array}{l}\text { Sex Contrast } \\
\text { Statistic (Sig.) }\end{array}$ & $\begin{array}{r}\text { Socio-economic } \\
\text { status (SES) }\end{array}$ & $\begin{array}{r}\text { Parental } \\
\text { closeness (PC) }\end{array}$ & Nationality (N) \\
\hline Positive space - teacher (PST) & $1.632(0.201)$ & $0.000(0.993)$ & $0.008(0.930)$ & $18.584(0.000)$ \\
\hline Negative space - teacher (NST) & $3.232(0.072)$ & $0.324(0.569)$ & $1.402(0.236)$ & $50.675(0.000)$ \\
\hline Positive space - peers (PSP) & $7.958(0.005)$ & $3.609(0.057)$ & $2.961(0.085)$ & $60.182(0.000)$ \\
\hline Negative space - peers (NSP) & $0.350(0.554)$ & $0.065(0.799)$ & $1.857(0.173)$ & $36.257(0.000)$ \\
\hline Positive space - self (PSS) & $1.636(0.201)$ & $0.702(0.402)$ & $0.541(0.462)$ & $24.296(0.000)$ \\
\hline Negative space - self (NSS) & $2.387(0.122)$ & $0.185(0.667)$ & $3.489(0.062)$ & $43.120(0.000)$ \\
\hline Perception of safety (PS) & $12.930(0.000)$ & $0.651(0.420)$ & $0.089(0.765)$ & $73.656(0.000)$ \\
\hline
\end{tabular}


In the Kruskal-Wallis test, the p-value for sex, socioeconomic status and parental closeness is more than 0.05 . There are a lack of significant differences in the opinions according to these variables. However, the p-value for nationality is $0.000<0.05$. Therefore, there is a significant difference in the opinions according to the nationality of the students.

\section{Discussion}

This study set out to investigate the perception and experience of safe learning space. There were two general hypotheses developed for the study. First, we hypothesize that female students with low socio-economic status and with low parental closeness perceive the school environment as unsafe $(\mathrm{H} 1)$. However, this hypothesis is not supported by the data. Firstly, the results show that there are no gender differences in the way in which students perceive a safe atmosphere in the classroom, which is in line with [39], who have not found evidence for correlation between gender and school safety fears. Other studies, however, have produced contrasting results. They $[33,35,36]$ found that female students are more likely to experience violence; therefore, girls report feeling unsafe at school; whereas, [37] and Welsh [38] have proved that male students more frequently perceive school as an unsafe environment. Secondly, concerning the family context, we have not found any correlation between parental involvement and the perception of safety, which is consistent with Hong and Eamon's study [33] but in contrast with [34] and [40]. Finally, in contrast to earlier studies $[33,39,41]$ we have not found any correlation between students' socio-economic status and feeling safe at school.

As mentioned earlier, no studies were found on how students from different cultural backgrounds perceive school safety. The results of the study revealed that there is a significant difference in the opinions in relation to the nationality of the students; therefore, the second hypothesis (H2: students' perceptions on safe space in education varies across cultures) has been supported. First, students differ in their opinions on why safe space should be created. The Polish students would like to form space at school for speaking their mind freely and discussing controversial issues. The Polish and Vietnamese students differ in their perception of the teacher's role in the classroom. For the Polish students, it is important that the teacher is respectful, supportive, open, is not biased nor judgmental, and encourages class participation. For the Vietnamese students, on the other hand, teachers build safe space if they are informative, knowledgeable, respectful and supportive. The respondents also differed in their opinions on disruptive teacher behavior. Teachers' reliance on the didactic format being abrupt or rude is more inconvenient for the Polish rather than the Vietnamese students. Both groups of students agree that teachers being critical towards students and biased and opinionated disrupts safety in the classroom. These differences may be accounted for in the educational experience of both groups. Polish students are invited to share opinions in the classroom despite the dominant traditional teaching style. However, in Vietnam, respect for authority and the collectivist culture result in an expectation that the teacher is the center of the classroom and the students listen in silence. Vietnamese students therefore do not feel insecure when their opinions are not required or sought after by the teacher, but might feel threatened by a teacher who positions the student at the center of a lecture.

The respondents also differed in their perception of the role of their peers in shaping atmosphere as the Poles believe that sharing thoughts and ideas mostly promotes a positive atmosphere, whereas the Vietnamese students pointed at the need for their classmates to have positive attitudes. This is reflected in cross-cultural differences where the Poles are increasingly individualistic, whilst Vietnamese culture is feminine and collectivist. Furthermore, Poland's educational system is focused on developing critical cognitive skills through individual work and high competitiveness, whilst schools in Vietnam foster unity and agreement in order to avoid conflict and challenges in order to maintain social harmony and societal rules.

Finally, the students differ in their opinion on their own role in shaping positive and negative space at school. The Polish students believe that being open-minded and honestly sharing ideas leads to a feeling of safety, whereas the Vietnamese students are more supportive towards others. The answer to this question clearly shows cross-cultural differences between the two groups. The Vietnamese students find it important to maintain social harmony, whilst the Poles are more self-assured, outspoken, and active in their pursuit of justice and fairness for the individual.

\section{Conclusions and Practical Implications}

The aim of the study was to investigate the associations between different individual student characteristics and the formation of safe educational space in a sample of undergraduate students from Poland and Vietnam. In particular, the study examined the effect of sex, nationality, and family context on students' perception of a safe learning environment. The study indicated that neither sex nor family context affects students' feeling of safety at school. However, feeling secure at school is considerably associated with nationality. Culture is therefore the key to understanding the perspectives which govern the principles underlying the approach to safe space in education. Not only do students from different cultural backgrounds have a different experience of how teachers and peers affect the formation of learning space at school, but they also have different expectations towards their own role in shaping a safe atmosphere at school.

These findings have significant implications for an understanding of how to shape a safe learning space. Feeling safe, supportive and risk-free is a prerequisite to forming an environment where students can assimilate knowledge, behavior, and thinking, as well as shape their attitudes, norms, values and opinions; consequently, it improves students' performance $[7,21,63]$. In a safe environment, students are encouraged to break out of their isolation, form collaborating classroom communities [12,19], and express themselves 
without fear. This is in line with the concept of cultural safety, which incorporates "an environment that is spiritually, socially and emotionally safe, as well as physically safe for people; where there is no assault challenge or denial of their identity, of who they are and what they need" [61]. Enhancing cultural safety entails not only treating every individual with respect but also empowering students to become more self-confident and effective as learners. Adopting such an approach will eventually enhance human security, and, as a result, ease tensions and intercultural conflicts [62,64]. Therefore, goals such as promoting respect for diversity and encouraging the student voice, as well as enhancing cultural awareness and competences, need to shape the hidden curriculum. It is important that learning space is a safe space where students feel secure to openly express their opinions, share their attitudes, and take risks so that their performance was enhanced and outcomes improved.

One source of weakness in this study which could have affected the findings was the small sample size. Future studies might carry out the analysis on a larger population. Another limitation is the overrepresentation of students from Poland, which was substantially higher than of students from Vietnam. The study also did not include age as a factor that might affect the perception of safe space. The last major limitation is that the theory of $G$. Hofstede was applied for our analyses; therefore, the conceptualization of culture reflected the interpretations of differences between Poland and Vietnam. Given the increasingly multicultural classrooms all over the world, the findings of the study

\section{References and Notes}

[1] Berry B, Byrd A, Wieder A. Teacherpreneurs: Innovative Teachers Who Lead but Don't Leave. John Wiley \& Sons; 2013.

[2] Herbert T. Learning Spaces, Learning Environments and the Dis'placement' of Learning. British Journal of Educational Technology. 2010;41(3):502-511. doi:10.1111/j.1467-8535.2009.00974.x.

[3] Bandura A. Social Learning Theory. Prentice Hall; 1977.

[4] Vygotsky L. Mind in Society. Harvard University Press; 1978.

[5] Lave J, Wenger E. Situated Learning: Legitimate Peripheral Participation. Cambridge University Press; 1991.

[6] Cross J. Informal Learning Rediscovering the Natural Pathways That Inspire Innovation and Performance. Pfeiffer; 2007.

[7] Savin-Baden M, McFarland L, Savin-Baden J. Learning Spaces, Agency and Notions of Improvement: What Influences Thinking and Practices about Teaching and Learning in Higher Education? An Interpretive Meta-ethnography. London Review of Education. 2008;6(3):211-237. doi:10.1080/14748460802489355.

[8] Biesta GJ. Beautiful Risk of Education. Routledge; 2016.

[9] Andrejuk K. Vietnamese in Poland: How does Ethnicity Affect Immigrant Entrepreneurship? Asian and Pacific Migration Journal. 2016;25(4):379-400. doi:10.1177/0117196816673843.

[10] Szymanska-Matusiewicz G. Migration and Cultural Flows between Vietnam and Poland. Asian and Pacific Migration Journal. 2016;25(3):275-295. doi:10.1177/0117196816654617.

[11] Flensner KK, Von der Lippe M. Being Safe from What and Safe for Whom?. A Critical Discussion of the Conceptual Metaphor of 'Safe Space'. Intercultural Education. 2019;30(3):275-288. doi:10.1080/14675986.2019.1540102.

[12] Biegel S. The Right to be Out: Sexual Orientation and Gender Identity in America's Public Schools. University of Minnesota Press; 2010.

[13] DePalma R, Atkinson E. 'No Outsiders': Moving beyond a Discourse of Tolerance to Challenge Heteronormativity in Primary Schools. British Educational Research Journal. 2009;35(6):837-855. have important implications for enhancing the education of students that are from different cultural backgrounds. Understanding the factors that undermine school safety helps to reduce the long-term negative outcomes of victimization at school and lower the risk of exposure to unsafe school environments. Developing school safety programs enhances school safety, supports the creation of cooperative school structure, supports relationships with peers and reinforces the appropriate behavior of both teachers and all school personnel. Furthermore, other studies suggest the need to establish and enforce fair rules to enhance school safety $[33,41]$, development of community programs aimed at reducing violence in the neighborhood [65], and intervening at the family, school and community levels [33]. Further work is needed to fully understand how students from different cultural backgrounds perceive and experience a safe learning environment, in particular the role of their teachers, of their peers and their own role in shaping the atmosphere at school. The correlation between school safety and individual characteristics or school context is complex.

\section{Acknowledgments}

This research was funded by War Studies University in Warsaw, Poland, grants number II.1.22.0 and II.1.15.0.

This research study was conducted as part of Dorota Domalewska's postdoctoral fellowship at Rangsit University, Pathum Thani, Thailand in 2019.

doi:10.1080/01411920802688705.

[14] Winton S. Managing Conduct: A Comparative Policy Analysis of Safe Schools Policies in Toronto, Canada and Buffalo, USA. Comparative Education. 2011;47(2):247-263. doi:10.1080/03050068.2011.554088.

[15] Turner C, Diver T. Safe Spaces at Universities are "Fundamentally offensive", says Oxford Chancellor. The Telegraph. 2017 November 4; Available from: https://www.telegraph.co.uk/education/2017/11/04/ safe-spaces-universities-fundamentally-offensive-says-oxford/.

[16] Weale S. Safe Spaces used to Inhibit Free Speech on Campuses, Inquiry Finds. The Guardian. 2018 Mar 27; Available from: https://www.theguardian.com/education/2018/mar/27/safespaces-used-to-inhibit-free-speech-on-campuses-inquiry-finds.

[17] Holley LC, Steiner S. Safe Space: Student Perspectives on Classroom Environment. Journal of Social Work Education. 2005;41(1):49-64. doi:10.5175/JSWE.2005.200300343.

[18] Gawlik-Kobylinska M. Can Security and Safety Education Support Sustainability? Lessons Learned from Poland. Sustainability (Switzerland). 2021;13(4):1-13. doi:10.3390/su13041747.

[19] Kislyakov P, Shmeleva E, Karaseva T, Silaeva O. Monitoring of Education Environment According to the Social-psychological Safety Criterion. Asian Social Science. 2014;10(17):285-293. doi:10.5539/ass.v10n17p285.

[20] Riekie H, Aldridge JM, Afari E. The Role of the School Climate in High School Students' Mental Health and Identity Formation: A South Australian Study. British Educational Research Journal. 2017;43(1):95-123. doi:10.1002/berj.3254.

[21] Haggis D. Influencing Positive Outcomes for Troubled Youth. Contemporary Issues in Education Research (CIER). 2017;10(3):179-184. doi:10.19030/cier.v10i3.9978.

[22] Abdou ED. Toward Embracing Multiple Perspectives in World History Curricula: Interrogating Representations of Intercultural Exchanges Between Ancient Civilizations in Quebec Textbooks. Theory and Research in Social Education. 2017;45(3):378-412. 
doi:10.1080/00933104.2016.1276500.

[23] Jackson R. SignpostsFIX ME!!!!: Policy and Practice for Teaching about Religions and Non-religious World Views in Intercultural Education. Council of Europe Publishing; 2014.

[24] Dweck C. Carol Dweck Revisits the Growth Mindset. Education Week. 2015;35(5):20-24. Available from: https://www.stem.org.uk/system/ files/community-resources/2016/06/DweckEducationWeek.pdf.

[25] Iversen LL. From Safe Spaces to Communities of Disagreement. British Journal of Religious Education. 2019;41(3):315-326. doi:10.1080/01416200.2018.1445617.

[26] Arao B, Clemens C. From Safe Spaces to Brave Spaces. A New Way to Frame Dialogue around Diversity and Social Justice. In: Landreman LM, editor. The Art of Effective Facilitation: Reflections from Social Justice Educators. Stylus Publishing; 2013. pp. 135-150.

[27] Bayeva IA. Provision of Psychological Safety in Educational Institution: A Practical Guide. Speech; 2006.

[28] Adayemo SA. The Relationship between Effective Classroom Management and Students' Academic Achievement. European Journal of Educational Studies. 2012;4(3):367-381.

[29] Velissaratou J. Framework for a Module on the Physical Learning Environment. Revised Edition. Organisation for Economic Co-operation and Development (OECD); 2017. Available from: http://www.oecd.org/education/OECD-FRAMEWORK-FOR-AMODULE-ON-THE-PHYSICAL-LEARNING-ENVIRONMENT.pdf.

[30] Filipek A. Family as a Fundamental Social Unit Shaping Security Culture: Polish Realities. Security and Defence Quarterly. 2020;30(3):95-107. doi:10.35467/sdq/125778.

[31] Urych I. Students' Opinion on the Academic Curriculum in Military Classes. Security and Defence Quarterly. 2018;18(1):26-44. doi:10.5604/01.3001.0011.8324.

[32] Astor RA, Meyer HA, Pitner RO. Elementary and Middle School Students' Perceptions of Violence-prone School Subcontexts. Elementary School Journal. 2001;101(5):511-528. doi:10.1086/499685.

[33] Hong JS, Eamon MK. Students' Perceptions of Unsafe Schools: An Ecological Systems Analysis. Journal of Child and Family Studies. 2012;21(3):428-438. doi:10.1007/s10826-011-9494-8.

[34] Hong JS, Voisin DR, Lee J. Urban African American Youth and Their Caregivers' Perceptions of School Safety in Chicago. Youth Violence and Juvenile Justice. 2018;16(2):174-189. doi:10.1177/1541204016680406.

[35] Zhang A, Musu-Gillette L, Oudekerk BA. Indicators of School Crime and Safety: 2015. National Center for Education Statistics; 2016. Available from: https://nces.ed.gov/pubs2016/2016079.pdf.

[36] Meyer EJ. A Feminist Reframing of Bullying and Harassment: Transforming Schools through Critical Pedagogy. McGill Journal of Education. 2008;43(1):33-48. doi:10.7202/019572ar.

[37] Akiba M. Predictors of Student Fear of School Violence: A Comparative Study of Eighth Graders in 33 Countries. School Effectiveness and School Improvement. 2008;19(1):51-72. doi:10.1080/09243450801936878.

[38] Welsh WN. The Effects of School Climate on School Disorder. The Annals of the American Academy of Political and Social Science. 2000;567(1):88-107. doi:10.1177/000271620056700107.

[39] Mijanovich T, Weitzman BC. Which "Broken Windows" Matter? School, Neighborhood, and Family Characteristics Associated With Youths' Feelings of Unsafety. Journal of Urban Health. 2003;80(3). doi:10.1093/JURBAN/JTG045.

[40] Wallace LH, May DC. The Impact of Parental Attachment and Feelings of Isolation on Adolescent Fear of Crime at School. Adolescence. 2005;40:457-474. Available from: https://pubmed.ncbi.nlm.nih.gov/ $16268126 /$

[41] Schreck CJ, Miller JM. Sources of Fear of Crime at School: What is the Relative Contribution of Disorder, Individual Characteristics, and School Security? Journal of School Violence. 2003;2(4):57-79. doi:10.1300/J202v02n04 04.

[42] Johnson B, Stevens JJ. Student Achievement and Elementary Teachers' Perceptions of School Climate. Learning Environments Research. 2006;9(2):111-122. doi:10.1007/s10984-006-9007-7.

[43] Bakioglu A, Geyin C. What Does School Size Do: Safety Perceptions of Educators and Students. US-China Education Review. 2009;6(10):1-8. Available from: https://eric.ed.gov/?id=ED511181.

[44] Bachman R, Randolph A, Brown BL. Predicting Perceptions of Fear at School and Going to and From School for African American and
White Students: The Effects of School Security Measures. Youth \& Society. 2011;43(2):705-726. doi:10.1177/0044118X10366674.

[45] Juvonen J, Nishina A, Graham S. Ethnic Diversity and Perceptions of Safety in Urban Middle Schools. Psychological Science. 2006;17(5):393-400. doi:10.1111/j.1467-9280.2006.01718.x.

[46] Antonio AL, Chang MJ, Hakuta K, Kenny DA, Levin S, Milem JF. Effects of Racial Diversity on Complex Thinking in College Students. Psychological Science. 2004;15:507-510. doi:10.2307/40064007.

[47] Domalewska D. Integration and Safety of Immigrant Students: Implications for Migration Governance. In: Soliman KS, editor. Education Excellence and Innovation Management: A 2025 Vision to Sustain Economic Development during Global Challenges. Proceedings of the $35^{\text {th }}$ International Business Information Management Association Conference (IBIMA). International Business Information Management Association (IBIMA); 2020. pp. 5543-5557.

[48] Moon RJ, Shin GW. International Student Networks as Transnational Social Capital: Illustrations from Japan. Comparative Education. 2019;55(4):557-574. doi:10.1080/03050068.2019.1601919.

[49] Veerasamy AK, Laakso MJ. Cultural Issues That Affect Computer Programming: A Study of Vietnamese in Higher Education. Asian Journal of Education and E-Learning. 2016:4(2). Available from: https://www.ajouronline.com/index.php/AJEEL/article/view/3655.

[50] Beugelsdijk S, Maseland R, van Hoorn A. Are Scores on Hofstede's Dimensions of National Culture Stable over Time? A Cohort Analysis. Global Strategy Journal. 2015;5(3):223-240. doi:10.1002/gsj.1098.

[51] Hofstede G. Cultures and Organizations-software of the Mind Profile Books Ltd.; 2003

[52] Hofstede G, Hofstede GJ, Minkov M. Cultures and Organizations: Software of the Mind. Intercultural Cooperation and Its Importance for Survival. McGraw-Hill; 2010.

[53] Hofstede G. Dimensionalizing Cultures: The Hofstede Model in Context. Online Readings in Psychology and Culture. 2011;2(1):1-8. doi:10.9707/2307-0919.1014.

[54] Thi Q, Nguyen N. The Vietnamese Values System: A Blend of Oriental, Western and Socialist Values. International Education Studies. 2016;9(12). doi:10.5539/ies.v9n12p32.

[55] McCauley B, Nguyen THT, McDonald M, Wearing S. Digital Gaming Culture in Vietnam: An Exploratory Study. Leisure Studies. 2020;39(3):372-386. doi:10.1080/02614367.2020.1731842.

[56] Oosterhoff P, Hoang T, Quach TT. Negotiating Public and Legal Spaces: The Emergence of an LGBT Movement in Vietnam, IDS Evidence Report 74; 2014. Available from: https://www.ids.ac.uk/publications/negotiating-public-andlegal-spaces-the-emergence-of-an-lgbt-movement-in-vietnam/.

[57] Nguyen M, Truong M. Procedia CIRP. vol. 40. Elsevier B.V.; 2016. pp. 680-686. 10.1016/j.procir.2016.01.154.

[58] Borowik I. Religion, Politics, and Social Attitudes in Transforming Poland: A Conclusion. In: Ramet SP, Borowik I, editors. Religion, Politics, and Values in Poland. Palgrave Macmillan; 2017. pp. 313-324. doi:10.1057/978-1-137-43751-8

[59] Marody M, Mandes S. Polish Religious Values as Reflected in the European Values Study. In: Religion, Politics, and Values in Poland. Palgrave Macmillan US; 2017. pp. 231-255. doi:10.1057/978-1-13743751-8 11 .

[60] Konopka K, Prusik M, Szulawski M. Two Sexes, Two Genders Only: Measuring Attitudes toward Transgender Individuals in Poland. Sex Roles. 2020;82(9-10):600-621. doi:10.1007/s11199-019-01071-7.

[61] Treas J, Tai T. Gender Inequality in Housework across 20 European Nations: Lessons from Gender Stratification Theories. Sex Roles. 2016;74(11-12):495-511. doi:10.1007/s11199-015-0575-9.

[62] Poland. Hofstede Insights; 2020. Available from: https://www. hofstede-insights.com/country/poland/.

[63] Kijkstra JK, Gest SD. Peer Norm Salience for Academic Achievement, Prosocial Behavior, and Bullying: Implications for Adolescent School Experiences. Journal of Early Adololescence. 2014;35(1):1-18. doi:10.1177/0272431614524303.

[64] Williams R. Cultural Safety - What Does it Mean for Our Work Practice? Australian and New Zealand Journal of Public Health. 1999;23(2):213-214. doi:10.1111/j.1467-842X.1999.tb01240.x.

[65] Pemunta NV, Nkongho EAR. The Fragility of the Liberal Peace Export to South Sudan: Formal Education Access as a Basis of a Liberal Peace Project. Journal of Human Security. 2014;10(1):59-75. doi:10.12924/johs2014.10010059 


\section{Appendix}

Table A1. Descriptive statistics of the study variables in the answers given by Polish [PL] and Vietnamese [VN] students.

\begin{tabular}{|c|c|c|c|}
\hline Variable & Questionnaire items & $\begin{array}{r}\text { Total \% agree or } \\
\text { strongly agree (PL; VN) }\end{array}$ & SD \\
\hline \multirow{10}{*}{$\begin{array}{l}\text { Positive space - teacher } \\
\text { (PST) }\end{array}$} & Q1 the teacher modelled participation and developed ground rules & Q1 $30.27(18.6 ; 11.6)$ & 1.00 \\
\hline & Q2 the teacher raised controversial ideas and was comfortable with conflict & Q2 $20.83(12.5 ; 8.3)$ & \\
\hline & Q3 the teacher encouraged or required class participation & Q3 $27.5(20.8 ; 6.6)$ & \\
\hline & Q4 the teacher challenged students, posed questions & Q4 $33.61(23.3 ; 10.2)$ & \\
\hline & Q5 the teacher was not biased, non-judgmental, open & Q5 $37.5(24.4 ; 13)$ & \\
\hline & Q6 the teacher was respectful and supportive of others' opinions & Q6 $46.94(31.1 ; 15.8)$ & \\
\hline & Q7 the teacher was friendly and caring & Q7 $32.22(16.6 ; 15.5)$ & \\
\hline & Q8 the teacher shared his or her personal opinions with the students & Q8 $18.88(4.1 ; 14.7)$ & \\
\hline & Q9 the teacher was informative and knowledgeable & Q9 $27.5(8 ; 19.4)$ & \\
\hline & Q10 the teacher was laid back, flexible, calm, or comfortable & Q10 $25.83(14.7 ; 11.1)$ & \\
\hline \multirow[t]{6}{*}{$\begin{array}{l}\text { Negative space - teacher } \\
\text { (NST) }\end{array}$} & $\begin{array}{l}\text { Q11 the teacher was critical towards students, chastised students, or 'shot } \\
\text { down' their ideas }\end{array}$ & Q11 $48.05(25 ; 23)$ & 0.89 \\
\hline & Q12 the teacher was biased, opinionated, or judgmental & Q12 $52.22(27.2 ; 25)$ & \\
\hline & Q13 the teacher did not consider others' perspectives & Q13 $39.44(21.3 ; 18)$ & \\
\hline & Q14 the teacher relied on didactic format & Q14 $39.44(25 ; 14.4)$ & \\
\hline & Q15 the teacher was abrupt / rude when disagreed with students & Q15 $28.61(18.8 ; 9.7)$ & \\
\hline & Q16 the teacher did not listen / respond to student comments & Q16 $36.38(16.6 ; 19.7)$ & \\
\hline \multirow{6}{*}{$\begin{array}{l}\text { Positive space - peers } \\
\text { (PSP) }\end{array}$} & Q17 my classmates were respectful, listened, followed ground rules & Q17 $45.27(23.6 ; 21.6)$ & 0.83 \\
\hline & Q18 my classmates honestly shared thoughts, ideas, opinions, and facts & Q18 $56.11(35.5 ; 20.5)$ & \\
\hline & $\begin{array}{l}\text { Q19 my classmates were non-judgmental and open to new ideas or } \\
\text { perspectives }\end{array}$ & Q19 $35.55(19.1 ; 16.3)$ & \\
\hline & $\begin{array}{l}\text { Q20 my classmates had a sense of community; they were friendly, supportive } \\
\text { and trustworthy }\end{array}$ & Q20 $38.05(20.8 ; 17.2)$ & \\
\hline & $\begin{array}{l}\text { Q21 my classmates encouraged me to think critically, they challenged my } \\
\text { thoughts }\end{array}$ & Q21 $26.11(15.5 ; 10.5)$ & \\
\hline & Q22 my classmates had positive attitudes & Q22 $47.77(24.1 ; 23.6)$ & \\
\hline \multirow{5}{*}{$\begin{array}{l}\text { Negative space - peers } \\
\text { (NSP) }\end{array}$} & Q23 my classmates did not speak or were afraid to speak & Q23 $61.38(13.3 ; 28.8)$ & 0.78 \\
\hline & Q24 my classmates were biased, judgmental, or close-minded & Q24 $44.44(32.5 ; 21.3)$ & \\
\hline & $\begin{array}{l}\text { Q25 my classmates were apathetic about the course (e.g. they did not attend } \\
\text { class, were unprepared for class) }\end{array}$ & Q25 $63.88(23 ; 27.2)$ & \\
\hline & Q26 my classmates tried to please the teacher & Q26 $46.11(36.6 ; 22.2)$ & \\
\hline & Q27 my classmates were frustrated, angry or hostile & Q2733.05 (23.8; 8.3) & \\
\hline \multirow{9}{*}{$\begin{array}{l}\text { Positive space - self } \\
\text { (PSS) }\end{array}$} & Q28 I tried to be open-minded and considered views of my classmates & Q28 $49.44(30.5 ; 18.8)$ & 0.86 \\
\hline & Q29 I honestly shared ideas, views, and values & Q29 $36.66(22.7 ; 13.8)$ & \\
\hline & Q30 I actively participated in discussion, spoke up & Q30 $37.77(19.1 ; 18.6)$ & \\
\hline & Q31 I was supportive of or respectful toward others & Q31 $40.55(19.1 ; 21.3)$ & \\
\hline & $\begin{array}{l}\text { Q32 I was prepared for class (e.g. completed readings, knowledgeable about } \\
\text { subject) }\end{array}$ & Q32 $25.83(16.6 ; 9.1)$ & \\
\hline & $\begin{array}{l}\text { Q33 I felt comfortable (e.g. comfortable with my classmates, encouraged by } \\
\text { peers and teacher) }\end{array}$ & Q33 $28.05(14.7 ; 13.3)$ & \\
\hline & Q34 I listened actively (e.g. I listened attentively, gave full attention to others) & Q34 $28.88(17.5 ; 11.3)$ & \\
\hline & $\begin{array}{l}\text { Q35 I used other discussion skills (e.g. raised hand, thought before speaking, } \\
\text { controlled voice tone) }\end{array}$ & Q35 $19.44(14.4 ; 5)$ & \\
\hline & Q36 I was invested in class (e.g. interested, excited, passionate) & Q36 $13.88(9.1 ; 4.7)$ & \\
\hline
\end{tabular}


Table A1. (Continuation).

\begin{tabular}{|c|c|c|c|}
\hline Variable & Questionnaire items & $\begin{array}{r}\text { Total \% agree or } \\
\text { strongly agree (PL; VN) }\end{array}$ & SD \\
\hline \multirow{4}{*}{$\begin{array}{l}\text { Negative space - self } \\
\text { (NSS) }\end{array}$} & Q37 I did not participate & Q37 $47.5(3.3 ; 18)$ & 0.90 \\
\hline & Q38 I was fearful, worried, intimidated, insecure & Q38 $55.55(29.4 ; 24.1)$ & \\
\hline & Q39 I was not confident & Q39 $63.88(31.3 ; 33)$ & \\
\hline & Q40 I did not invest in the course (e.g. 'tuned out', bored, skipped class) & Q40 $46.94(30.8 ; 22.5)$ & \\
\hline \multirow[t]{5}{*}{ Perception of safety (PS) } & $\begin{array}{l}\text { Q41 it is important to create safe space in the classroom where students can } \\
\text { freely speak their mind }\end{array}$ & Q41 $86.38(48.6 ; 37.7)$ & 3.29 \\
\hline & Q42 I think students should be encouraged to discuss different perspectives & Q42 $77.77(40 ; 37.7)$ & \\
\hline & $\begin{array}{l}\text { Q43 I think the teacher and students should set some ground rules to enable } \\
\text { safe space in the classroom to discuss controversial issues }\end{array}$ & Q43 $74.16(38 ; 36.1)$ & \\
\hline & $\begin{array}{l}\text { Q44 I would like to engage in discussion on controversial issues with my } \\
\text { classmates and the teacher }\end{array}$ & Q44 $61.94(34.1 ; 27.7)$ & \\
\hline & $\begin{array}{l}\text { Q45 I think discussing controversial issues can develop critical thinking and } \\
\text { individual choices }\end{array}$ & Q45 $67.77(33 ; 34.7)$ & \\
\hline \multirow[t]{2}{*}{ Sex } & Male & 39.4 & \\
\hline & Female & 60.6 & \\
\hline \multirow{2}{*}{$\begin{array}{l}\text { Socio-economic status } \\
\text { (SES) }\end{array}$} & High & $87.5(86.3 ; 89)$ & \\
\hline & Low & $12.5(13.7 ; 11)$ & \\
\hline \multirow[t]{2}{*}{ Parental closeness (PC) } & High & $41(42.4 ; 38.8)$ & \\
\hline & Low & $58.9(57.5 ; 60.4)$ & \\
\hline \multirow[t]{2}{*}{ Nationality } & Polish & 61.4 & \\
\hline & Vietnamese & 38.6 & \\
\hline
\end{tabular}

Note. $N=360$ 